\title{
Mental Models in Human-Environment Interactions: Theory, Policy Implications, and Methodological Explorations
}

\author{
Timothy Lynam $^{1}$ and Katrina Brown ${ }^{2}$
}

Key Words: human-environment; mental models

This collection of papers focuses on the application of methods to elicit and analyze mental models or social representations, that is, representations of the world that are shared by social groups. Mental models represent the way in which people understand the world around them; they are the internal representation of the external system. Mental models are the cognitive structure upon which reasoning, decision making, and behavior are based. However, importantly, mental models are models, and this means that they are incomplete, and they are often inconsistent representations of reality. They are also dynamic, i.e., they change over time, they are able to adapt to changing circumstances, and may also evolve over time through learning. Currently there is much interest in mental models in human-environment interactions and natural resource management. Elucidating mental models helps us to understand and delineate different conceptualizations of how a system works: the interactions between factors or components, the critical issues, and the causal links. Only when we can effectively elucidate and analyze mental models can we begin to explore how they affect behavior. This in turn might help to develop more appropriate management strategies within a given context. Studying mental models can help us to understand both individual conceptualizations and also collective beliefs or representations. To date in natural resource management the exploration of mental models has sought to assess the degree to which these conceptualizations are internally coherent, i.e., the extent of their coherence with an external reality, and to explore alternative representations. A range of different methods and techniques have been used. The interest in mental models can be viewed as an intrinsic part of more participatory approaches to environmental governance and natural resource management currently underway around the world.

This is certainly the case in South Africa, and indeed the Water Act and the catchment-level water management strategies enshrined within it have been hailed as a landmark in legislation for greater stakeholder inclusion in resource management. Although the context and setting of the workshop examining water management in South Africa are extremely important, the discussions in the papers in this special feature have relevance and hopefully find resonance with many different geographical settings and scales. The issues discussed and the interrogation of methods have much broader applicability. The methods themselves and the investigation of mental models can be applied to communities of place as well as communities of practice. In addition, some of the methods have been tested in other contexts and the reports of these applications greatly enrich the learning that is reflected in this special feature.

In 2006 a mental models group was established within the Resilience Alliance to explore the contributions that different stakeholders and stakeholder groupings make to natural resources dynamics and the resilience of social-ecological systems. A study of water management practices associated with the National Water Act in South Africa provided an excellent opportunity to study mental models, and to assess the application of different methods for studying them, and the role that improved understanding of mental models could make in integrated water resource management at the catchment and other scales. It was felt in particular that the development of multistakeholder water management in the form of Catchment Management Agencies within the context of the National Water Act increased the potential relevance of understanding mental models and their consequences for water resource management. A central part of the collaborative research process that produced these papers was a 10-day long intensive workshop held in Mpumalanga Province of South Africa. The workshop was not only a data gathering and method testing exercise. Importantly it was an interdisciplinary learning experience with shared explorations of methods, theory, and ultimately the analysis of mental models of human-environment interactions.

There were good reasons to choose the Inkomati Catchment as the site for the empirical research reported in these papers. Among these were the extent of existing research and good access to and knowledge of social and professional networks. However, even with the links to these established networks of knowledge and practice and with the direct involvement of individuals with long experience of the context, there was still not enough time to complete a full suite of techniques prescribed by the methods tested. This highlights one of the core lessons from this research exercise: that the process of 
elucidating and eliciting mental models is resource intensive, in terms of time, skills, people, and other resources. It also demands much from the participants in the research. The experience of undertaking the research activities in this project underscores for us the levels of commitment, trust, and painstaking communications necessary to apply the types of methods discussed in the papers. A key question for future research on mental models is the extent to which methods and techniques can be streamlined: to determine the depth and breadth of analysis necessary, the feasibility of conducting intensive short-duration empirical data collection exercises, and the quality of information obtained from them.

Research so far on mental models exposes further significant gaps in theory, process, methods, and application to policy and practice. The analyses reporting in the following papers attempt to address some of these issues. Many challenging and fascinating lines of inquiry remain. For example, we touch on, but do not develop, the role of the elicitation process itself in construction of peoples' mental models; the delineation, interactions, and dynamics of individual and collective models; and a consideration of how stable models may be over time, how rapidly they might change in different circumstances.

The seven papers explore different aspects of application of mental models. The first paper, by Lynam et al. (2012), presents a synthesis of the major learning in the application of elicitation and analysis of two methods in South Africa and their extension in France. The paper compares the application of the two methods used, i.e., Actors, Resources, Dynamics, and Interactions (ARDI) and Consensus Analysis, and relates the important findings to current theory to identify key gaps in our collective understanding. It discusses the procedural dimensions, the strengths and challenges, similarities and differences between them. They ask different questions. It discusses the appropriateness of the methods in different contexts and the potential sequential use in the South African water policy. The next paper, by Jones et al. (2011) presents a theoretical and conceptual overview of mental models. It analyzes the emergence of research on mental models within different fields, and how different disciplinary traditions have researched them. The third and fourth papers present the results of applying the two methods in the field in South Africa. Stone-Jovicich et al. (2011), examines the application of the Consensus Analysis method, originating as a technique in anthropology, examining the degree of consensus within and between two key stakeholder groups, conservationists and irrigators. It uses quantitative techniques including factor analysis, cluster analysis, and multidimensional scaling to analyze data from interviews, freelists, and pilesorts. Etienne and colleagues (2011) explore the outcomes of the ARDI method, a method that is based on participatory workshops that co-construct a dynamic model, and sets out to collaboratively identify adaptive management systems. The final paper in the South African set, by Du Toit et al. (2011), discusses the potential utility of the methods within the context of South Africa's National Water Act. The Integrated Water Resource Management framework provides for collaborative strategic planning, shared visioning, water use regulation, and implementation of plans.

Two additional papers provide rich extensions of both the consensus method and of ARDI. The paper by Mathevet et al. (2011) describes the application of the consensus analysis method to data collected using the ARDI process in the Camargue, France. The paper highlights the potential to link these two methods and provides intriguing glimpses of how group mental models change through interaction in a management context. The last paper, by Meredith Gartin and colleagues (2010), looks at the application of consensus analysis in an urban environment. What this paper does that none of the others do is demonstrate the potential to start explaining the knowledge that different individuals in a population hold. This means we can start to explore the characteristics of the most knowledgeable and least knowledgeable members of a group.

This set of papers represents some exciting first steps in what we hope is a bountiful journey of exploration. There is much to be learned.

Responses to this article can be read online at: http://www.ecologyandsociety.org/voll7/iss3/art24/ responses/

\section{LITERATURE CITED}

Du Toit, D. R., H. Biggs, and S. Pollard. 2011. The potential role of mental model methodologies in multistakeholder negotiations: integrated water resources management in South Africa. Ecology and Society 16(3):21. http://dx.doi.org/10.5751/ ES-04237-160321

Etienne, M., D. R. Du Toit, and S. Pollard. 2011. ARDI: a coconstruction method for participatory modeling in natural resources management. Ecology and Society 16(1):44. [online] URL: http://www.ecologyandsociety.org/vol16/iss1/ $\underline{\operatorname{art} 44 /}$

Gartin, M., B. Crona, A. Wutich, and P. Westerhoff. 2010. Urban ethnohydrology: cultural knowledge of water quality and water management in a desert city. Ecology and Society 15(4):36. [online] URL: http://www.ecologyandsociety.org/vol15/ iss4/art36/

Jones, N. A., H. Ross, T. Lynam, P. Perez, and A. Leitch. 2011. Mental models: an interdisciplinary synthesis of theory and methods. Ecology and Society 16(1):46. [online] URL: http:// www.ecologyandsociety.org/vol16/iss1/art46/ 
Lynam, T., R. Mathevet, M. Etienne, S. Stone-Jovicich, A. Leitch, N. Jones, H. Ross, D. Du Toit, S. Pollard, H. Biggs, and P. Perez. 2012. Waypoints on a journey of discovery: mental models in human-environment interactions. Ecology and Society 17(3):23. http://dx.doi.org/10.5751/ES-05118-170323

Mathevet, R., M. Etienne, T. Lynam, and C. Calvet. 2011. Water management in the Camargue Biosphere Reserve: insights from comparative mental models analysis. Ecology and Society 16(1):43. [online] URL: http://www.ecologyands ociety.org/vol16/iss1/art43/

Stone-Jovicich, S. S., T. Lynam, A. Leitch, and N. A. Jones. 2011. Using consensus analysis to assess mental models about water use and management in the Crocodile River Catchment, South Africa. Ecology and Society 16(1):45. [online] URL:

http://www.ecologyandsociety.org/vol16/iss1/art45/ 